\title{
Levantamento da Diversidade de Aves em Áreas Urbanas na Cidade de Maringá - PR
}

\author{
Diversity Survey of Birds in Urban Areas in the City of Maringá - PR
}
Levantamiento de la Diversidad de Aves en Áreas Urbanas en la Ciudad de Maringá $-P R$

\author{
Marcelo Tenório Crepaldi ${ }^{1}$ \\ Mateus Fachin Pedroso ${ }^{2}$ \\ Maria Eugênia Moreira Costa Ferreira ${ }^{3}$
}

\begin{abstract}
RESUMO: O presente estudo possui um enfoque biogeográfico de reconhecimento, e análise da avifauna urbana, nativa e exótica de áreas distintas dentro da cidade de Maringá - PR. O objetivo deste estudo é o levantamento da diversidade de espécies avícolas encontradas no meio urbano, bem como a identificação de distintos hábitats e nichos ecológicos. É de destaque que, a partir dos resultados obtidos, as espécies identificadas são detentoras de alta capacidade de adequação ao meio urbano, já que as mesmas se depararam com fatores essenciais para fazer da urbe um novo hábitat.
\end{abstract}

PALAVRAS-CHAVE: Biogeografia. Avifauna. Áreas Urbanas.

ABSTRACT: The present study has a biological focus and recognition of the urban, native and exotic bird wildlife of distinct areas within the city of Maringá - PR. The objective of this study is the survey of the diversity of poultry species found in the urban environment, as well as the identification of different habitats and ecological niches. It is noteworthy from the results obtained, that as identified species are of high capacity of adaptation to the urban environment, since as if they are faced with essential factors to make a new habitat of city.

KEYWORDS: Biogeography. Bird wildlife. Urban areas.

RESUMEN: El presente estudio tiene un enfoque biológico y reconocimiento de la avifauna urbana, nativa y exótica de áreas distintas dentro de la ciudad de Maringá - PR. El objetivo de este estudio es el levantamiento de la diversidad de especies avícolas encontradas en el medio urbano, así como la identificación de distintos hábitats y nichos ecológicos. Es de destaque a partir de los resultados obtenidos, que como especies identificadas son de alta capacidad de adecuación al medio urbano, ya que como se han encontrado con factores esenciales para hacer de urbe un nuevo hábitat.

PALABRAS CLAVES: Biogeografía. Avifauna. Áreas urbanas.

\footnotetext{
${ }^{1}$ Programa de Pós-Graduação em Geografia da Universidade Estadual de Maringá, Campus de Maringá - PR. Av. Colombo, 5.790, Cep: 87020-900, Maringá - PR. E-mail: tenriomarcelo@gmail.com.

2 Programa de Pós-Graduação em Geografia da Universidade Estadual Paulista, Campus de Presidente Prudente - SP. Rua Roberto Simonsen, 305, Cep:19060-900, Presidente Prudente, SP. E-mail: mateus_fachin@hotmail.com.

${ }^{3}$ Universidade Estadual de Maringá. Universidade Estadual de Maringá, Campus de Maringá - PR.

Av. Colombo, 5.790, Cep: 87020-900, Maringá - PR. E-mail: eugeniaguart@hotmail.com.
} 


\section{INTRODUÇÃO}

De acordo com Paula e Ferreira (2005) a cidade de Maringá, que teve em seu cerne o ser uma cidade projetada, é intitulada de "cidade verde" e detentora de um vasto sistema viário, com suas avenidas e ruas amplamente arborizadas e com a preocupação de se estabelecer e manter áreas de proteção ambiental. A vegetação encontrada no município é categorizada como Floresta Estacional Semidecidual da região sul do país, que apresenta um alto número de espécies de aves endêmicas. Se levarmos em conta que a oferta de áreas verdes está ligada à diversidade taxonômica das aves, pressupõe-se que a vegetação nativa ou exótica dentro das áreas urbanas tem grande participação no conjunto das espécies encontradas em determinado meio (GALINA; GIMENES, 2006).

O presente estudo possui um enfoque biogeográfico de reconhecimento, levantamento e análise da avifauna urbana, exótica e nativa de áreas distintas dentro da cidade de Maringá - PR, a fim de realizar levantamento, registro, catalogação e análise dos hábitos alimentares e diversidade das espécies de aves, portanto o presente estudo teve como objetivo pesquisar como a avifauna explora determinado ambiente, identificando, catalogando e observando as características biogeográficas das mesmas.

Segundo Rodrigues et al. (2005) o levantamento de espécies avícolas é o princípio e o fundamento para a conservação deste grupo de animais, por isso a importância deste trabalho ao catalogar e levantar as diferentes espécies encontradas nas áreas estudadas. Em concordância a este pensamento Dickman (1987) ressalta que as áreas urbanas oferecem uma conjuntura favorável para o estudo de comunidades de diferentes espécies de aves, e que determinado ambiente, além de promover sensíveis mudanças no meio original, se fraciona nos mais diferentes formatos e proporções, com estratos vegetais frequentemente alterados e diversas maneiras de antropização promovidas pelo ser humano.

Pautado nas premissas citadas, os métodos utilizados para a produção deste estudo, para fins de observação e registro, envolveram saídas de campo para investigação das diferentes espécies encontradas. A identificação se deu através de registros fotográficos. Foi utilizada a bibliografia relacionada ao tema para servir como arcabouço e base sólida para a realização da pesquisa. 


\section{DESENVOLVIMENTO}

Para a produção do respectivo estudo foram estabelecidos objetivos junto à um cronograma e planos de trabalho a serem seguidos, e que envolveram as distintas fases do mesmo. Em um primeiro momento foram estabelecidos recursos e materiais utilizados para sua fundamentação e efetuação.

Foi de grande importância a utilização de bibliografia relacionada ao tema, materiais fotográficos, do Sistemas de Informação Geográfica (SIG's) para a localização e visualização das áreas de estudo, bem como a utilização de softwares como: planilhas eletrônicas, $\mathrm{Br}$ Office 3.2 e de um banco de dados com relação das espécies avícolas a nível nacional. A partir disso foi criado um perfil do utilizador, e registros fotográficos foram enviados durante o trabalho, registros estes publicados na plataforma mediante a análise de profissionais que confirmam a veracidade das fotos.

Posteriormente à delimitação dos recursos utilizados, a parte funcional do estudo começou a ser trabalhada. Em um primeiro momento foi feita a utilização do Google Earth para a delimitação de áreas a serem estudadas e, a partir das imagens de satélite, foram então percorridas as respectivas zonas e paralelamente foram sendo realizados os registros fotográficos e a coleta de elementos referentes a cada espécie encontrada, segundo o método de Furlan (2005).

As áreas urbanas definidas para realização do estudo foram: o campus da Universidade Estadual de Maringá, a Avenida Mario Clapier Urbinati, localizada no bairro Zona 7, uma área particular conhecida como Cemitério Parque e por fim o bairro conhecido como Zona 27. Posteriormente ao estabelecimento das zonas urbanas a serem percorridas, fichas para a catalogação das espécies foram elaboradas com o recurso de planilhas eletrônicas e, por fim, foram iniciadas as incursões à campo nas áreas pré-estabelecidas.

Durante as incursões foram coletados registros fotográficos e dados sobre as espécies encontradas, utilizando as fichas desenvolvidas previamente e que continham dados como nome das espécies (científico e comum), horário de registro, local de registro, hábitos alimentares, coloração da ave e região de hábitat natural (FURLAN, 2005).

A autora citada descreve um comportamento a ser seguido para fazer o registro de espécies avícolas. O método se constitui através da permanência por parte do observador durante certo tempo em lugares que tenham atrativos para as aves como: rios, lagos e árvores com frutos e sementes, para que então o registro das espécies possa ser mais facilmente realizado. Furlan (2005) ainda descreve uma série de materiais úteis para registro e para melhorar as condições de análise durante a incursão ao campo. Determinados registros são feitos mediante uma trilha a ser seguida pelo observador, portando os seguintes materiais: 
Máquina fotográfica; GPS para marcar as coordenadas exatas dos pontos visitados; Boné para evitar luz sobre os olhos, e melhorar a luminosidade do binóculo; Lanternas para as observações noturnas, e outras menores de reserva; Fitas coloridas impermeáveis para marcar pontos na mata; Relógio com cronômetro; Lista de aves do local (alguns lugares, parques e reservas já possuem lista de sua avifauna, o que ajuda a observação, porque permite identificar melhor e mais rapidamente as aves avistadas); Caderno de anotações para as anotações e posterior estudo das espécies de difícil identificação; Pequeno gravador para registrar o canto das aves; Guia de campo para uma boa identificação, lembrado que deve ser escolhido o local que tem o maior número possível da avifauna do ecossistema escolhido; Roupas: devem ser discretas para não espantar as aves; tons de verde ou marrom são adequados para camuflar-se com o ambiente; Modo de andar: deve ser cauteloso e silencioso. Gestos rápidos assustam as aves, ao passo que andar em câmara lenta permite boa aproximação. Andar direto em direção a uma ave pode assustá-la, mas andar em zig-zag, como se estivesse apenas passando perto delas não as assusta tanto (FURLAN, 2005, p. 128).

Subsequentemente à realização dos registros visuais foram iniciadas as etapas laboratoriais de análise das espécies em relação aos ambientes estudados, tendo como base a catalogação realizada por meio do banco de dados estabelecido no Br.Office 3.2 e, em um momento posterior, a criação de planilhas eletrônicas, para melhor visualização dos resultados obtidos. Com a análise dos resultados obtidos nas áreas urbanas se tornou viável então a observação da incidência de diferentes espécies (apresentadas nas figuras 01), e em que áreas trabalhadas foram encontradas as maiores variedades e frequência das aves nos meios estudados. 
Figura 1 - Espécies encontradas
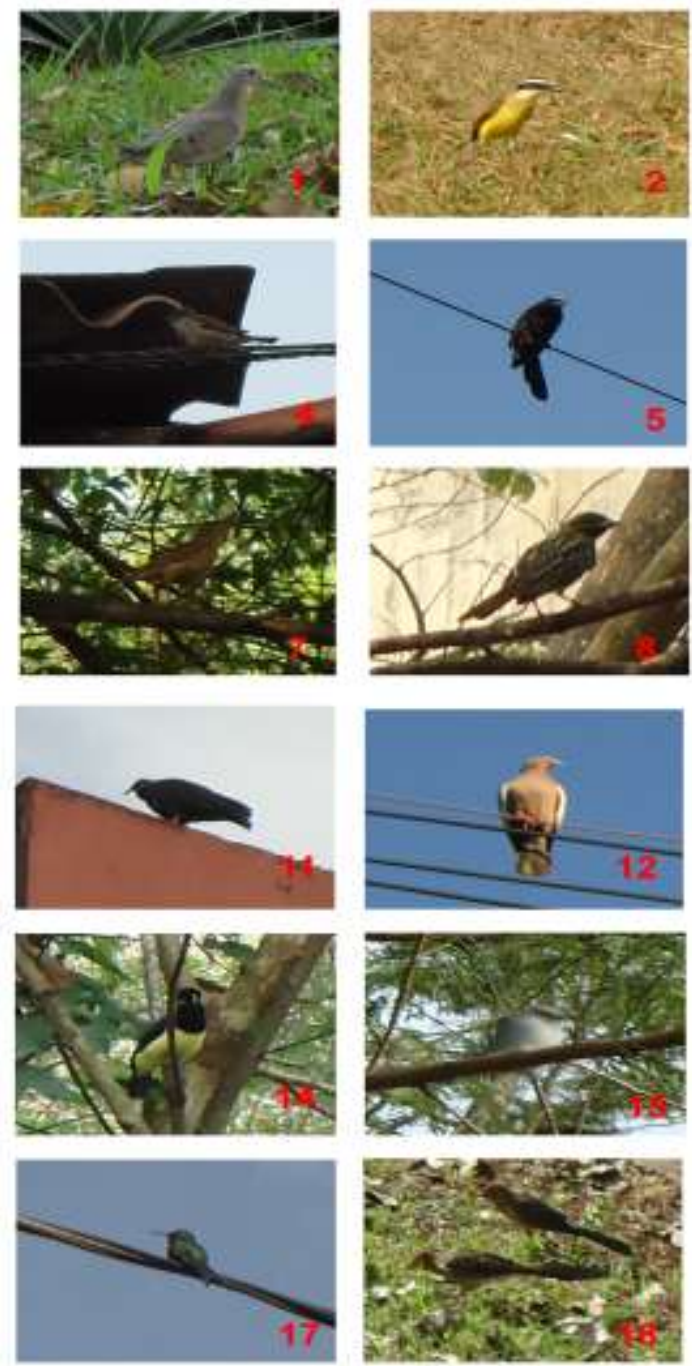

Fonte: Dados da pesquisa.

\section{Caracterização das Áreas de Estudo}

\section{Campus da Universidade Estadual de Maringá}

A Universidade Estadual de Maringá (Figura 2) está situada ao norte do município de Maringá - PR. O campus da universidade possui mais de 1 milhão de metros quadrados, e uma área verde abundante distribuída entre os blocos, se fazendo presente em todo território da faculdade, além de áreas descampadas e abertas compostas por campos de futebol, e ainda o Horto Florestal Dr. Luiz Teixeira Mendes.

Brun, Link e Brun (2007) e Argel-de-Oliveira (1990) reforçam a influência da vegetação urbana sobre as populações de aves. A partir dessa análise podemos destacar como fatores do estudo de aves no campus a grande área verde presente no local, e também o fato da grande circulação de pessoas, culminando com uma grande presença de alimentos e lixo. 
Figura 2 - Campus da Universidade Estadual de Maringá

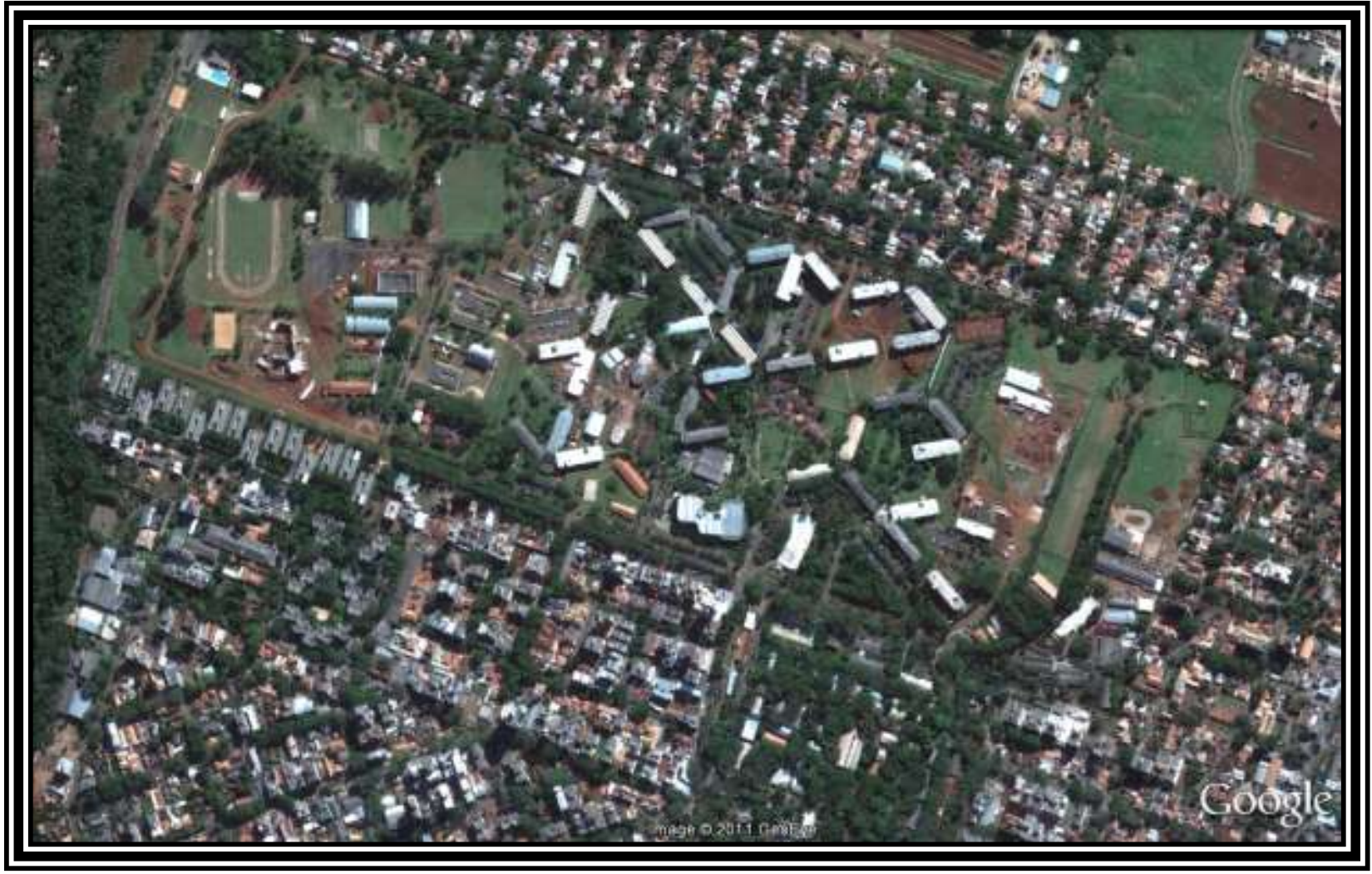

Fonte: Google (2011).

Foram tiradas 20 fotografias de espécies distribuídas no campus da universidade. As fotos foram tiradas de forma aleatória e sem interferência no meio biótico em que a ave estava ou com edição dos registros fotográficos.

\section{Corredor da Avenida Mario Clapier Urbinati}

O corredor em questão (Figura 3 ) foi previamente definido devido às especificidades encontradas durante o percurso. A avenida corta o bairro conhecido como Zona 7 do município de Maringá - PR. A área analisada da via pública em questão se estende por aproximadamente 1,85 quilômetros, vai desde a rotatória da mesma com a avenida Mandacaru até o fim da avenida que se dá em frente aos portões da Universidade Estadual de Maringá.

Durante o percurso destaca-se, em relação à sua paisagem, o córrego Mandacaru, em uma área de baixa vertente. O córrego é acompanhado por uma vegetação de galeria que contorna sua margem. Nota-se também na área em questão uma vasta área de pastagem e descampada, pertencente a uma propriedade rural particular. Deve-se salientar ainda que durante o período em que foram realizados os registros fotográficos foram iniciadas obras na propriedade mencionada anteriormente, o que nos faz pensar na possibilidade de 
interferência dos resultados devido à presença de maquinário que porventura pode diminuir a frequência de aves no local.

Figura 3 - Avenida Dr. Mario Clapier Urbinati

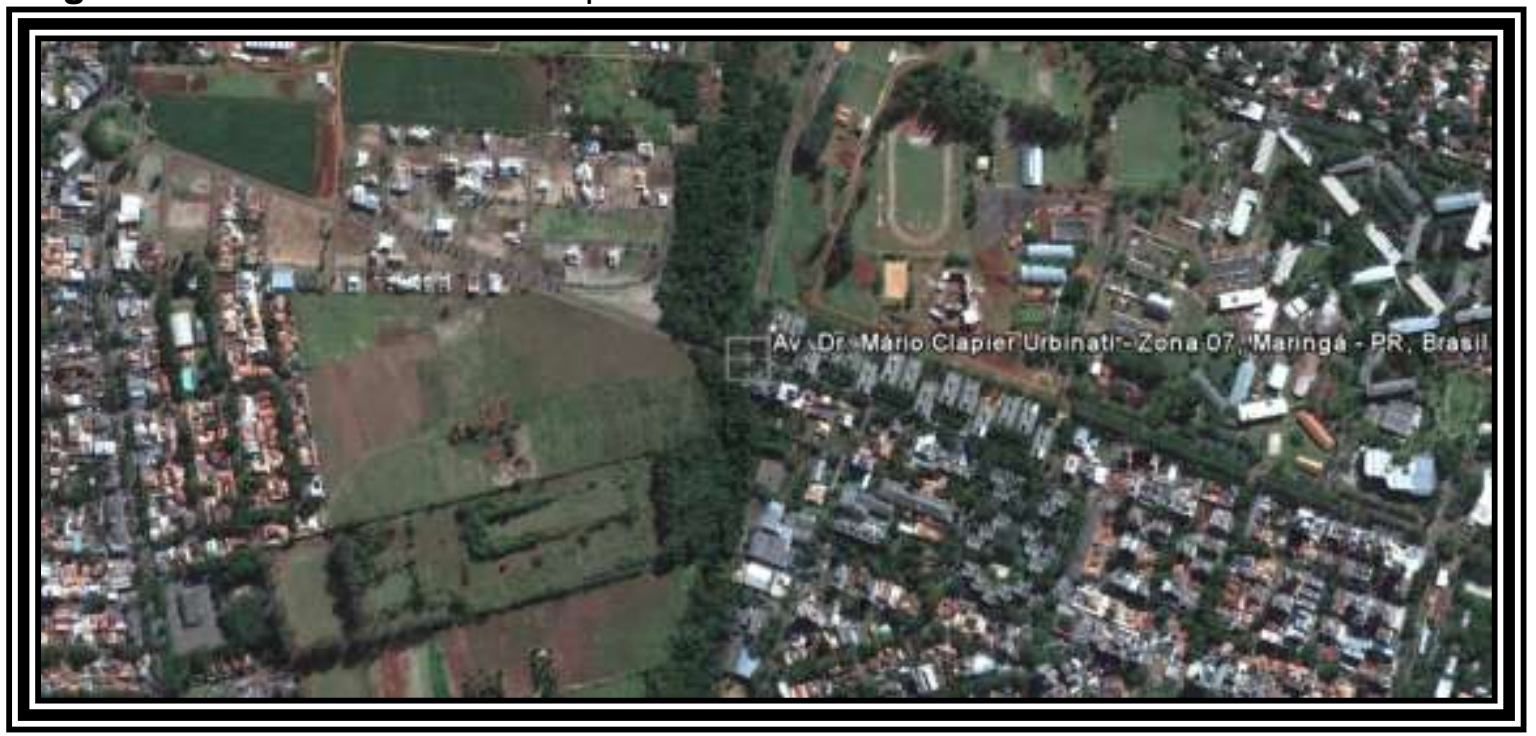

Fonte: Google (2011).

Foi tomado como local de estudo este corredor devido ao fato do mesmo possuir hábitats e nichos ecológicos diversos, como área de campo e uma galeria, fornecendo a presença de água, organismos, animais e insetos, fontes de alimento para espécies avícolas, culminando na permanência das mesmas no local. Foram tirados 20 registros fotográficos de espécies encontradas no local para futura análise e comparação com as outras localidades estipuladas neste trabalho.

\section{Cemitério Parque}

A área particular conhecida como Cemitério Parque (Figura 4) se localiza no município de Maringá - PR, mais precisamente na Avenida Alziro Zarur, no bairro conhecido como Zona 21. O cemitério foi inaugurado no mês de julho do ano de 1985 e possui uma área que abrange cerca de dez hectares, com área de sepultamento e uma edificação onde é locado o crematório.

A localidade foi avaliada e tomada uma etapa de estudo devido ao fato de que, dos seis alqueires que possui dois serem de mata nativa, e poderia abrigar diferentes espécies que não são encontradas nas outras localidades.

Há dois ambientes ecológicos distintos dentro da propriedade: o de mata nativa e o de área descampada (área das sepulturas). Foram realizados novamente nesta área 20 registros fotográficos para futura análise. 
Figura 4 - Cemitério Parque

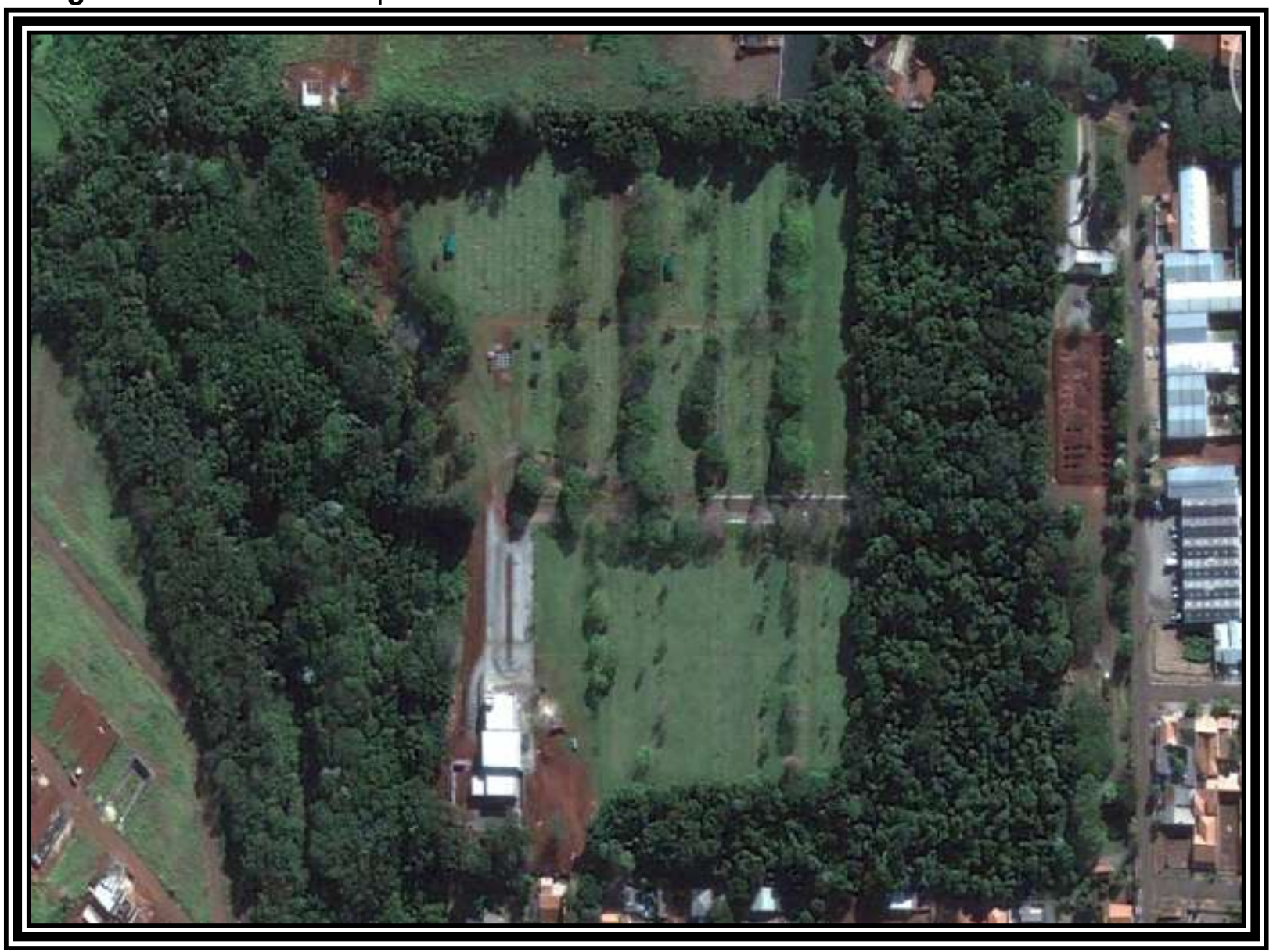

Fonte: Google (2011).

\section{Zona 27}

A localidade em questão (Figura 5) está situada na cidade de Maringá - PR, que constitui uma área da cidade densamente urbanizada, com muitas edificações, em sua maioria residências, apresentando também escolas e pequenos estabelecimentos comerciais em sua composição.

A área escolhida como objeto de análise possui característica urbana domiciliar, tal característica corrobora com o intenso fluxo de pessoas que contrasta com a vegetação urbana. Esta área localiza-se em um fundo de vale e é cortada pelo Córrego Mascado, sendo detentora então de dois ambientes distintos para os quais a avifauna pode ir se instalar. Destacamos que, na presente área estudada, foram realizadas também 20 registros fotográficos, a fim de estabelecer a futura análise das espécies encontradas. 
Figura 5 - Zona 27

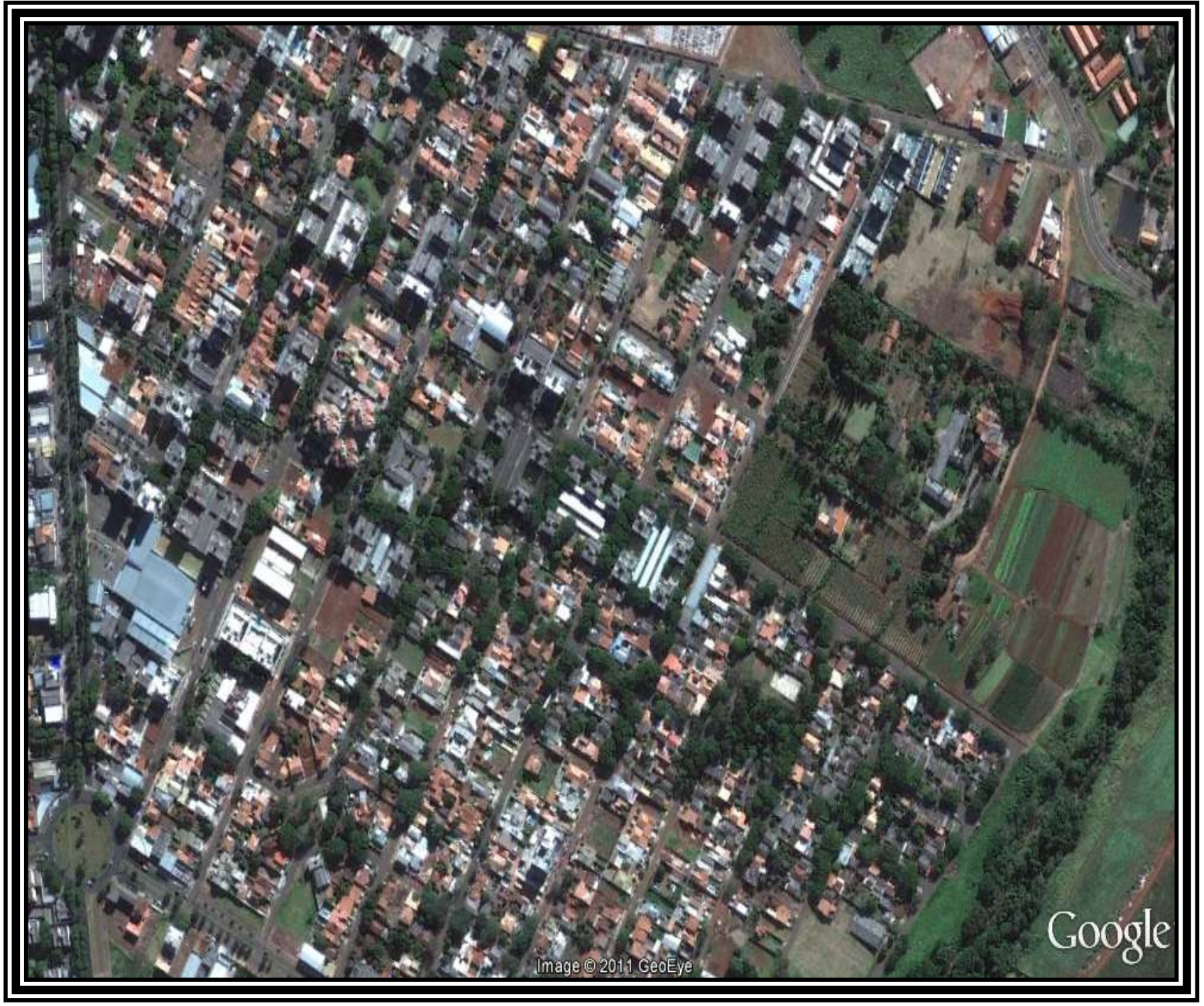

Fonte: Google (2011).

\section{Resultados nas Áreas Urbanas}

A análise e discussões dos resultados se deram a partir da relação do território e das espécies encontradas, uma vez que as espécies estão relacionadas com as características de cada área, fazendo com que as aves encontrassem possíveis subsídios para adaptação e instalação.

Foram encontradas nove ordens diferentes, dentre elas uma variedade de dezesseis famílias e vinte gêneros diferentes (Quadro 1), espalhadas nas quatro áreas estudadas da cidade de Maringá - PR. 
Quadro 1 - Ordem, Família e Gênero das espécies encontradas nas áreas estudadas

\begin{tabular}{lll}
\hline Ordem & Família & Gênero \\
\hline Apodiforme & Trochilidae & Thalurania \\
Cathartiforme & Cathardidae & Coragyps \\
Charadriiforme & Charadriidae & Vanellus \\
Columbiforme & Columbidae & Columba \\
& & Patagioenas \\
& Zenaida & Crotophaga \\
Cuculiforme & Cuculidae & Guira \\
& Caracara \\
Falconiforme & Colconidae & Cyanocorax \\
Passeriforme & Furnariidae & Furnarius \\
& Hirundinidae & Hirundo \\
& Mimidae & Mimus \\
& Motacillidae & Antgus \\
& Passeridae & Passer \\
& Thraupidae & Conirostrum \\
& Tyrannidae & Pitangus \\
& & Tyrannus \\
Piciforme & Picidae & Campephilus \\
Strigiformes & Strigidae & Athene \\
\hline
\end{tabular}

Fonte: Dados da pesquisa.

\section{Campus da Universidade Estadual de Maringá}

A partir das análises dos resultados obtidos na área do campus da Universidade Estadual de Maringá, foram elaborados dois gráficos. O primeiro (Figura 6) foi realizado a partir da variação de espécies encontradas na área em questão e sua respectiva frequência, o segundo gráfico (Figura 7) foi obtido através dos dados que demonstram a frequência dos hábitos alimentares das aves encontradas na área.

As espécies encontradas na área foram: Zenaida auriculata, Pitangus sulphuratus, Vanellus chilensis, Passer domesticus, Crotophaga ani, Mimus saturninus, Furnarius rufus, Anthus lutescens e Campephilus robustus. A área da Universidade Estadual de Maringá foi o local em que mais se obteve uma gama de espécies diferentes totalizando 9 indivíduos distintos.

Com a análise do primeiro gráfico pode-se verificar a maior incidência de três espécies distintas: Zenaida auriculata (pomba-de-bando), Pitangus sulphuratus (bem-te-vi) e Vanellus chilensis (quero-quero), respectivamente com uma incidência de $30 \%$, 25\% e 15\%, o que está diretamente relacionado com o conteúdo expresso no segundo gráfico, refletindo os hábitos alimentares de cada espécie. 
Figura 6 - Frequência de espécies encontradas na área.

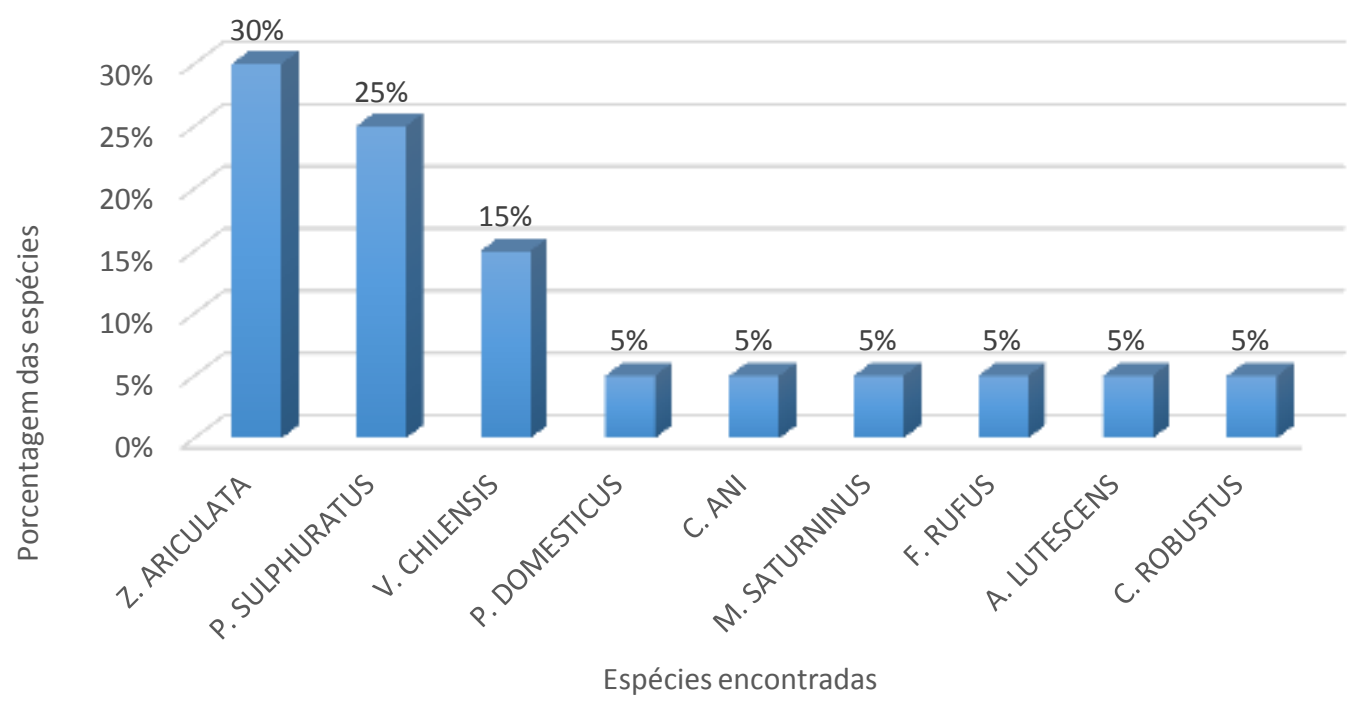

Fonte: Dados da pesquisa.

Figura 7 - Espécies encontradas de acordo com hábitos alimentares

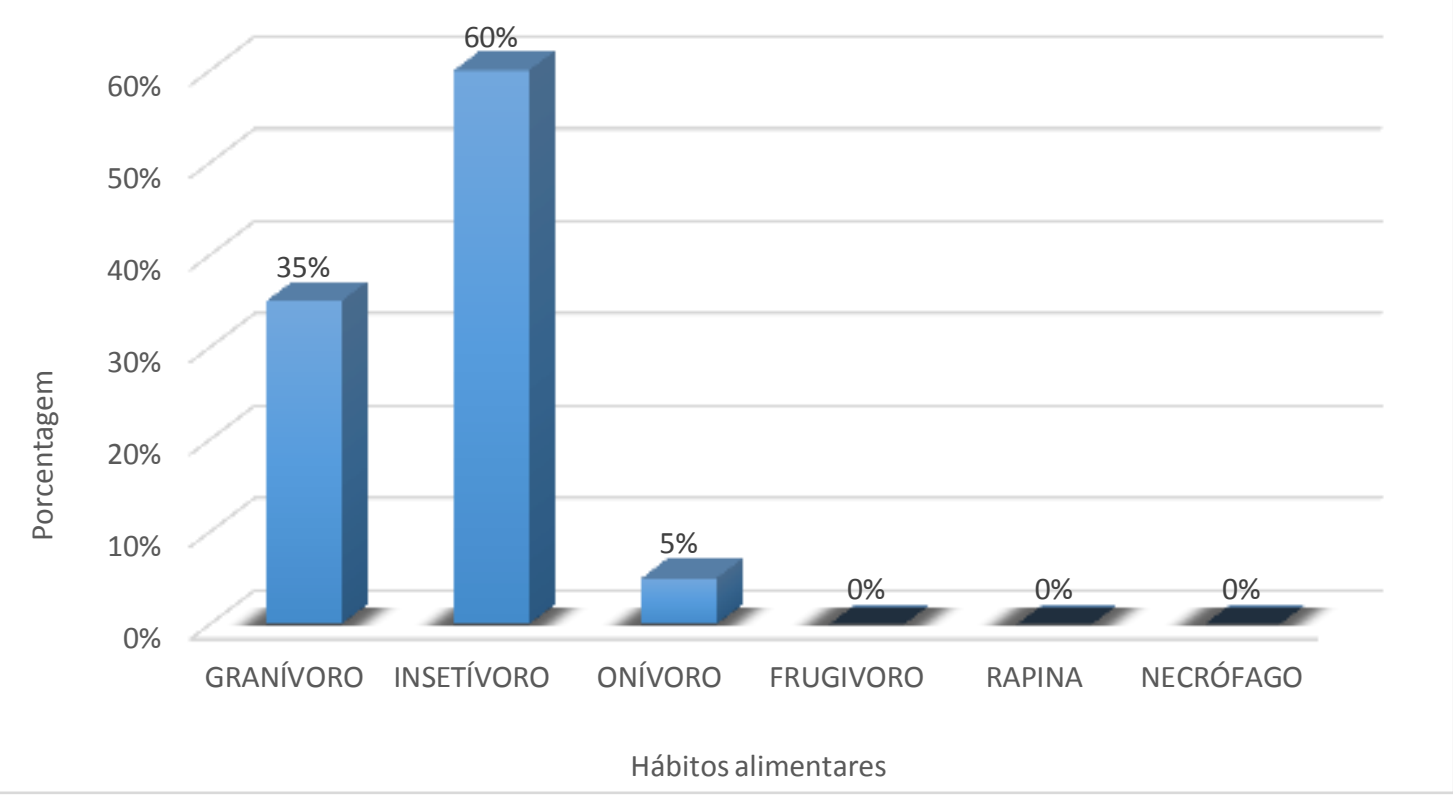

Fonte: Dados da pesquisa.

O segundo gráfico demonstra $60 \%$ de aves insetívoras e $35 \%$ de aves granívoras. As espécies que fazem com que a frequência seja alta de granívoros é a Zenaida auriculata, e a de insetívoros os indivíduos Pitangus sulphuratus e Vanellus chilensis, os outros demonstrados em minoria no primeiro gráfico.

A grande quantidade de animais granívoros se dá ao fato da grande presença de área verde no campus, o que incentiva este grupo de animais a se alimentar de sementes e frutos produzidos por diversas espécies arborícolas. 
As flores presentes na vegetação, assim como seus frutos, e a grande circulação de pessoas que produzem lixo derivado de restos orgânicos servem como atrativo alimentar para os insetos, e fazem com que a população de aves insetívoras seja grande no local.

Dentro das espécies insetívoras é interessante notar a presença da espécie Vanellus chilensis, conhecida popularmente como quero-quero, que faz uso da geografia do campus, mais especificamente dos ambientes de campo aberto (o campo de futebol, por exemplo), para ali se instalar, procurando alimento e alocando seus ovos em meio à vegetação rasteira.

É de suma importância o destaque de uma ave encontrada durante os registros na área, o pica-pau-rei (Campephilus robustus), que no caso foi encontrado procurando alimento (insetos em meio às cascas das árvores). Tal espécie é de difícil registro em uma área urbana por ser uma ave que costuma habitar florestas com árvores de médio e grande porte, mas na ocasião foi encontrada se alimentando no campus dentro da cidade.

\section{Corredor Avenida Dr. Mario Clapier Urbinati}

Após a elaboração dos gráficos de variedade de espécies (Figura 8), e o de variação de hábitos alimentares das espécies (Figura 9), foram realizadas relações entre a incidência das espécies e o território em questão, assim como a frequência de aves pelos hábitos alimentares a partir da fisiologia apresentada pelo ambiente. As espécies encontradas na área foram: Columba lívida, Zenaida auriculata, Coragyps atratus, Pitangus sulpurathus, Passer domesticus e Patogenias picaruzo.

De acordo com a análise dos gráficos elaborados, foi constatada a presença em maioria da espécie Zenaida auriculata (Figura 8), o que reflete diretamente na quantidade de aves granívoras mostradas no gráfico (Figura 9). Deve se destacar também a presença da espécie Pitangus sulpurathus, que reflete diretamente a taxa de $20 \%$ de aves insetívoras no local.

Nota-se também a classe de hábito alimentar necrófago na área em questão, no caso representada pela espécie Coragyps atratus (urubu-de-cabeça-preta), avistada mais precisamente no fundo do vale, no topo de uma edificação, a alguns metros do curso de água que corta a área.

Conclui-se que a maioria das espécies são granívoras e insetívoras devido à área verde presente no local. Os atrativos que esta área possui em relação à alimentação dos pássaros (sementes, frutos e insetos), decorre do fato de possuir um curso hídrico que atrai diferentes espécies adaptadas ao meio urbano, por exemplo, a ave necrófaga acima mencionada, que assim como outras utiliza o Córrego Mandacaru como fonte de hidratação. 
Figura 8 - Frequência de espécies encontradas

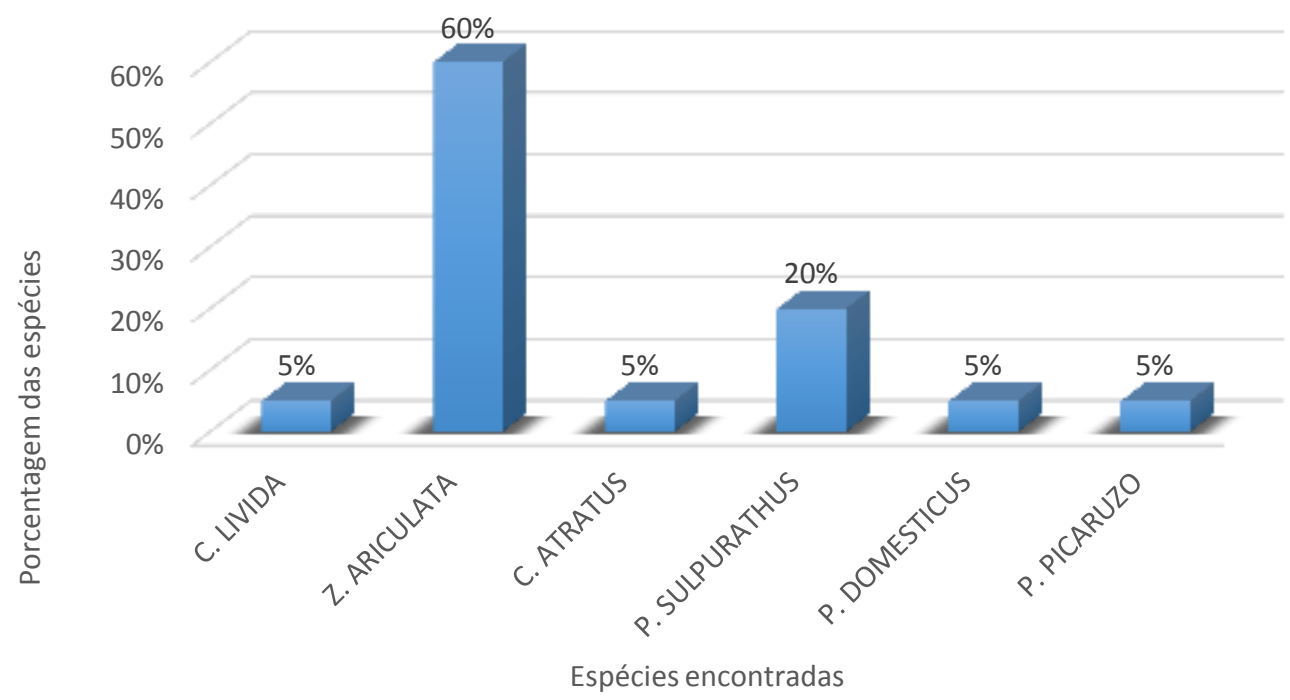

Fonte: Dados da pesquisa.

Figura 9 - Espécies encontradas de acordo com hábitos alimentares

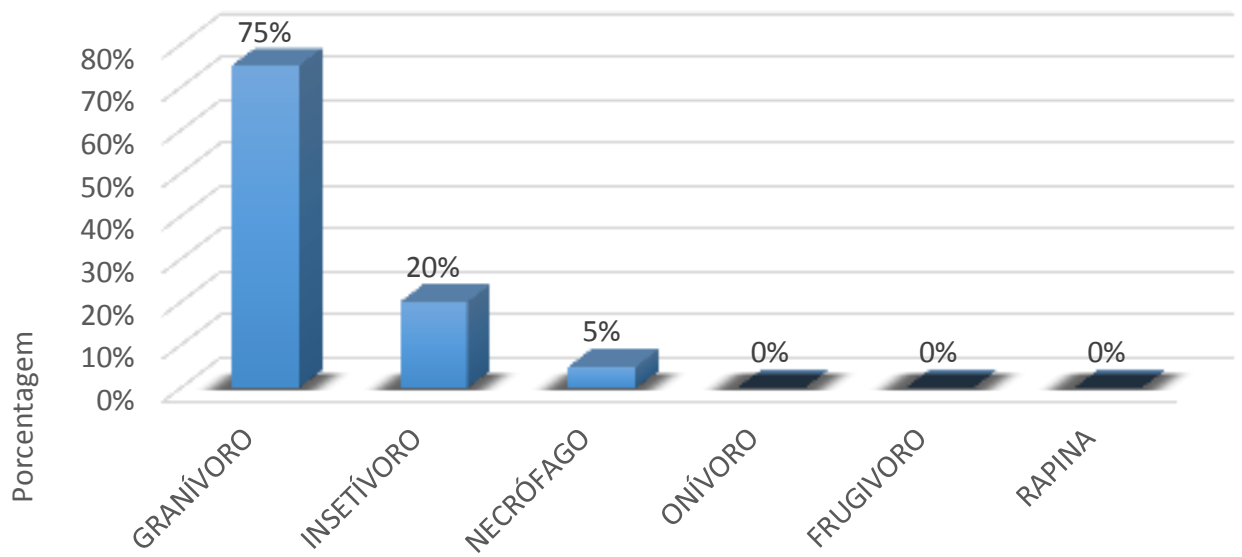

Hábitos alimentares

Fonte: Dados da pesquisa.

Está área foi uma das que se mais esperava a obtenção de variedade de espécies dentro das áreas de caráter urbano, o que não foi constatada devido ao fato da presença de obras na área agrícola, o que possivelmente afugentou as espécies devido à grande circulação de maquinário e trabalhadores.

\section{Cemitério Parque}

Mediante análise dos gráficos que esboçam os resultados referentes ao estudo das espécies na área (Figura 10 e 11), foram estabelecidas relações entre o ambiente e as espécies. 
Figura 10 - Frequência de espécies encontradas na área

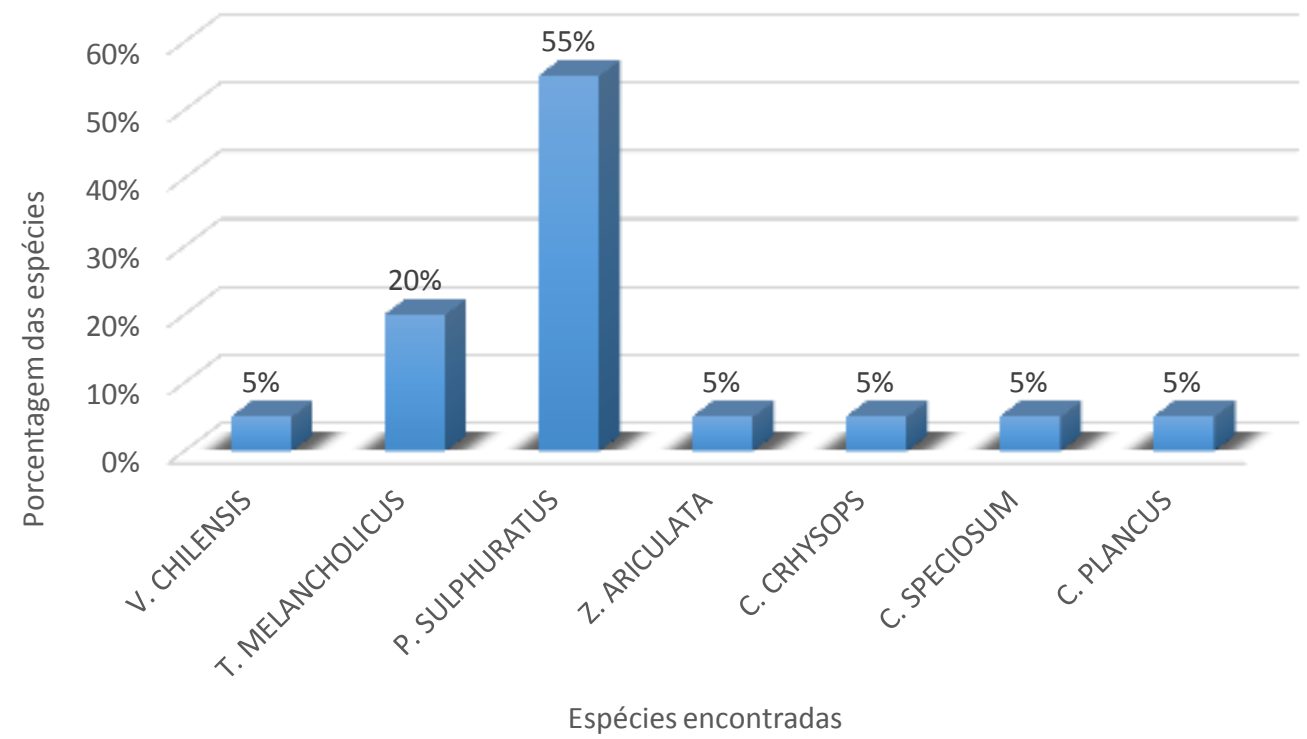

Fonte: Dados da pesquisa.

Foram encontradas na área as seguintes espécies: Vannelus chilenses, Tyrannus melancholicus, Pitangus Sulphuratus, Zenaida auriculata, Cyanocorax chrysops, Conirostrum speciosum e Caracara planus.

Realizada a análise notou-se a frequência de duas espécies que se destacam (Figura 10), Pitangus sulphuratus e Tyrannus melancholicus, ambas da família Tyrannidae, insetívoras, que justificam os dados ilustrados na Figura 11. Tais dados denotam que 95\% das espécies encontradas possuem esse hábito alimentar (não excluindo as outras espécies insetívoras encontradas).

A grande incidência de animais insetívoros se dá pelo fato da vasta presença de mata nativa e a atração que a mesma gera devido à quantidade de insetos alocados em meio à vegetação, e de uma área descampada, na qual insetos se alimentam da vegetação rasteira (como lagartas por exemplo). É de destaque a presença de uma ave da familia dos falconiformes, o "carcará" (Caracara plancus), que ali se encontrava provavelmente a procura de invertebrados e pequenos vertebrados para alimento, devido também ao fato da altura da copa das árvores de grande porte onde o mesmo costuma se instalar.

Encontrou-se também na área as espécies Zenaida auriculata (pomba-de-bando) e Cyanocorax chyrisops (gralha-picaça), ambas responsáveis pelos $5 \%$ de hábitos granívoro expresso no gráfico (Figura 11) referente à alimentação (alimento ofertado também pela vegetação local).

Nota-se também a presença da espécie Vanellus chilensis, o quero-quero, que se instalou na área descampada do cemitério em meio das sepulturas, fazendo aquela área de 
fisiologia diferente da de mata nativa um lugar de procura de alimentos e para procriação (fazendo ninhos na grama).

Figura 11 - Espécies encontradas de acordo com hábitos alimentares.

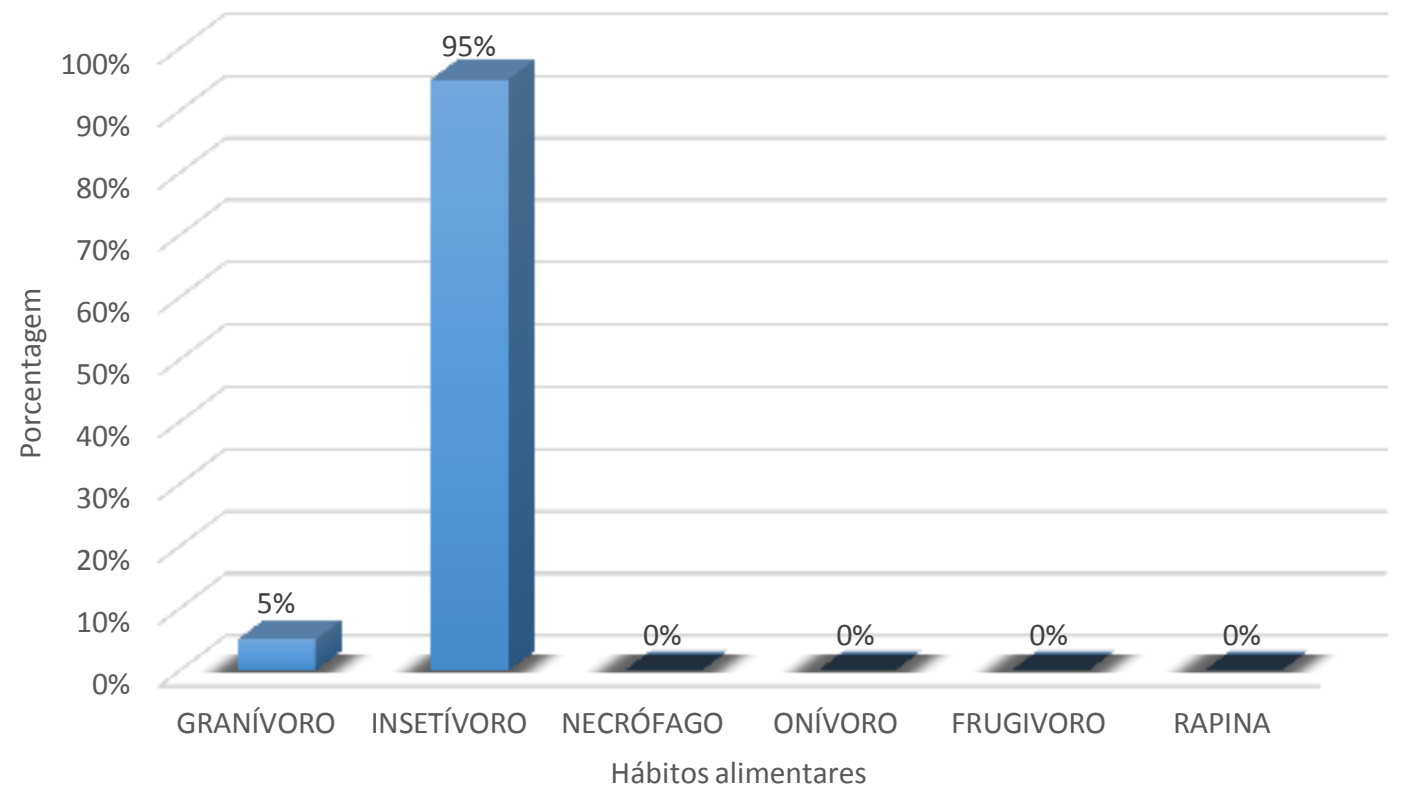

Fonte: Dados da pesquisa.

\section{Zona 27}

Posteriormente à coleta de dados, os mesmos foram utilizados para a elaboração dos gráficos que seguem (Figura 12 e 13), e assim foram feitas as análises. As espécies avícolas encontradas na área em questão foram: Thalurania glaucops, Patogenias picaruzo, Zenaida auriculata, Crotophaga ani, Guira guira, Hirundo rustica, Passer domesticus e Athene cunicularia.

Foram encontrados ao todo oito indivíduos de espécies diferentes nesta área, o que a caracterizou como a segunda maior área em variedades de espécies avícolas. Ao analisar a Figura 12, nota-se que quatro espécies distintas merecem destaque de acordo com sua incidência: Zenaida auriculata, Passer domesticus, Crotophaga ani e Thalurania glaucopis.

A partir da análise da Figura 13, observa-se a grande presença de animais granívoros (65\%) representados principalmente pelas espécies Zenaida auriculata e Passer domesticus, e de animais insetívoros (20\%) representados especialmente pelas espécies Guira guira, Crotophaga ani e Hirundo rustica.

Observa-se nessa área em questão dois hábitos alimentares ainda não vistos em outras áreas. Foram encontradas aves frugívoras (que se alimentam de néctar como Thaulurania glaucopis, o beija-flor-de-fronte-violeta, que provavelmente estava se 
alimentando em meio aos ipês encontrados no bairro), e de espécies de rapina, como é o caso da coruja buraqueira (Athene cunicularia), que foi registrada em um lugar de relevo plano em sua toca, mais precisamente numa área descampada de uma central de energia.

Figura 12 - Frequência de espécies encontradas na área

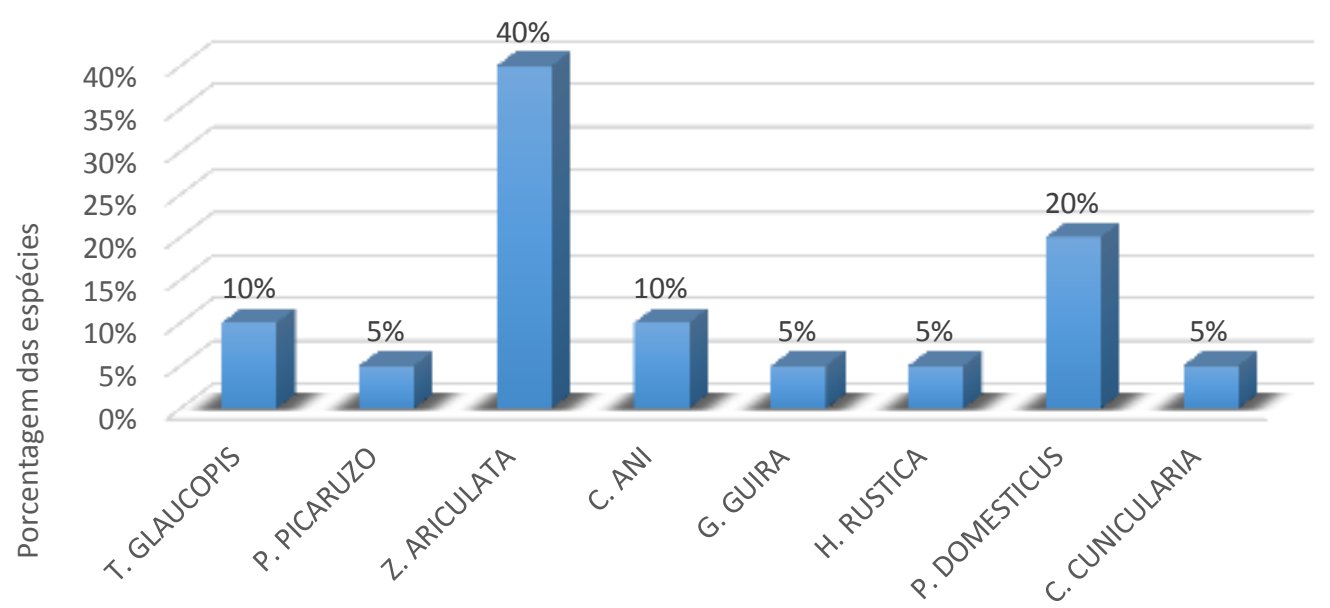

Espécies encontradas

Fonte: Dados da pesquisa.

Figura 13 - Espécies encontradas de acordo com hábitos alimentares

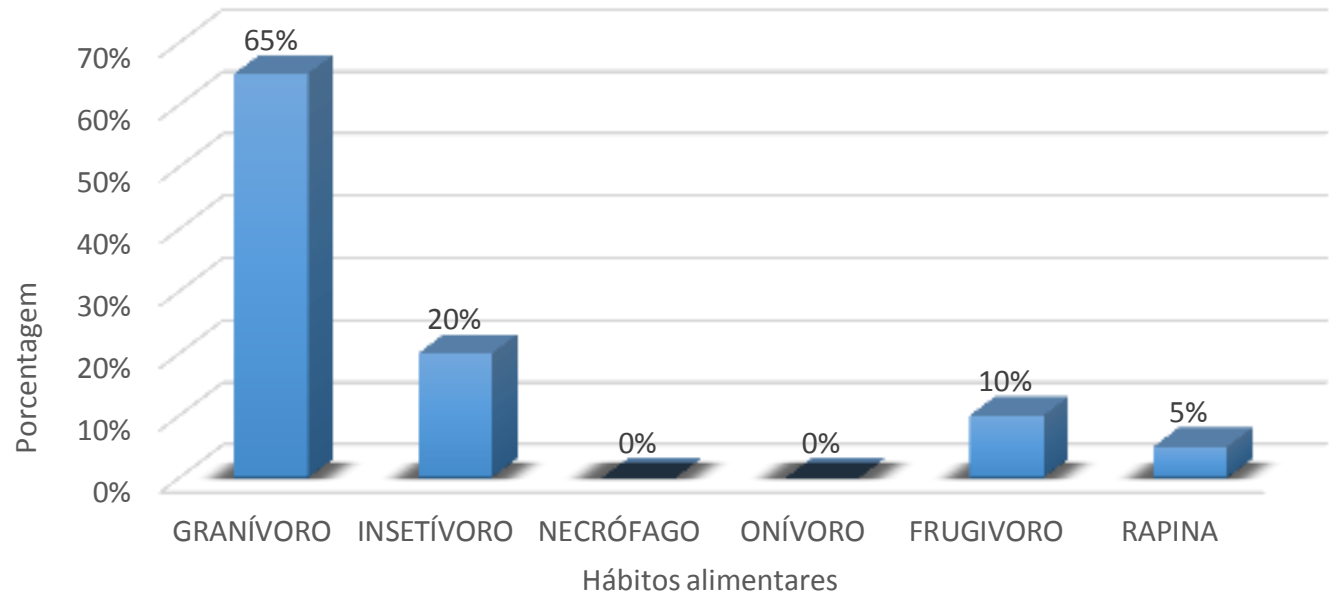

Fonte: Dados da pesquisa.

Conclui-se então que, neste ambiente em questão, fora as espécies encontradas que não são de comum frequência, como as citadas acima, as aves que mais se destacaram foram duas: Zenaida Auriculata e Passer domesticus. Ambas possuem uma grande adaptação ao meio urbano devido ao fato de encontrarem abrigo com extrema facilidade, em marquizes, em edificações feitas pelo homem e em meio à vegetação urbana, o mesmo acontece com os alimentos que podem ser encontrados derivados da vegetação ou gerados pelo homem. 


\section{CONSIDERAÇÕES FINAIS}

Foram realizadas todas as etapas propostas mediante a metodologia descrita anteriormente, realizando levantamentos, registros, catalogações e análises dos hábitos alimentares, bem como a diversidade das espécies de aves encontradas nas áreas estudadas, mantendo uma relação direta com suas adaptações às paisagens urbanas.

Mediante a produção e análise dos gráficos de diversidade de hábitos alimentares e de espécies, concluiu-se que determinadas espécies possuem maior facilidade para adaptação e consequentemente são encontradas em maior incidência dentro do cidade.

Dentre todas as espécies identificadas notou-se a presença de duas espécies em maior escala, a Zenaida auriculata e a Pitangus sulphutarus, ambas respectivamente com hábitos alimentares granívoro e insetívoro. Seguidamente é de importante ressalte, principalmente com relação à frequência, o Passer domesticus, o Vanellus chilensis e o Tyrannus melancholicus, os três respectivamente de hábitos alimentares granívoros, e os dois últimos também insetívoros.

É válido destacar, a partir dos resultados obtidos, que as espécies anteriormente citadas são detentoras de grande capacidade de adequação ao meio urbano, e que esta aptidão se deve ao fato das mesmas se depararem com fatores cruciais para fazer da urbe um novo hábitat, onde também possam sustentar-se. A facilidade na adaptação se dá pelo fato dos pássaros em questão encontrarem o nescessário para fazer da cidade um hábitat onde podem subsistir. Portanto podemos inferir que a cidade de Maringá é detentora de características atrativas às espécies, principamente no que se refere ao alimento e à moradia.

Determinadas espécies de aves, como é o caso da Zenaida auriculata (pomba-debando), se torna uma amostra real de adaptação, visto que a mesma por natureza se alimenta de grãos, e posteriormente desenvolveu uma variante alimentar, consequência do grande fluxo de pessoas responsáveis pelo descarte de restos de alimentos.

Atentamos também com este estudo a presença de aves exóticas de regiões de florestas fechadas, e que foram aqui encontradas como é o caso do pica-pau-rei (Campephilus robustus).

Em decorrência deste estudo é possível inferir então que as aves podem se adaptar com sucesso ao meio urbano, buscando diferentes fisiologias paisagísticas onde possam se instalar. A cidade se torna então uma possiblidade de hábitat.

A natureza então se adapta à transformação do ambiente, visto que, antes da ação do homem, espécies avícolas já se alimentavam e se reproduziam. Com a chegada do homem, seus meios e técnicas de produção, e sua ânsia por desenvolvimento, foram criadas 
diferentes paisagens onde as aves buscam se adaptar, possuindo além de seu meio nativo, agora situado em áreas de preservação, um ambiente urbano que, no caso de Maringá, possui uma vegetação planejada que oferta então possibilidades de características que podem usufruir para sobreviver.

\section{REFERÊNCIAS}

ARGEL-DE-OLIVEIRA, M. M. A. Arborização e avifauna urbana em cidades do interior paulista. Boletim do Centro de Estudos Ornitológicos, São Paulo, v. 7, n. 10, p. 10 - 15, 1990.

BRUN, F. G. K; LINK, D.; BRUN, E. J. O emprego da arborização na manutenção da biodiversidade de fauna em áreas urbanas. Revista da Sociedade Brasileira de Arborização Urbana, Piracicaba, v. 2, n. 1, p. 117-127, 2007.

DICKMAN, C. R. Habitat fragmentation and vertebrate species richness in an urban environment. Journal of Applied Ecology, London, v. 14, p. 337-351, 1987.

FURLAN, S. A. Técnicas de biogeografia. In: VENTURI, L. A. B. (Org.). Praticando geografia: técnicas de campo e laboratório. São Paulo: Oficina de Textos, 2005. p. 164 165.

GALINA, A. B.; GIMENES, M. R. Riqueza, composição e distribuição espacial da comunidade de aves em um fragmento florestal urbano em Maringá, Norte do Estado do Paraná, Brasil. Acta Scientiarum. Biological Sciences, Maringá, v. 28, n. 4, p. 379 - 388, 2006.

GOOGLE. Google Earth. Versão 6.1.0.5001. 2011. Google Inc. Disponível em: <https://www.google.com.br/earth/download/gep/agree.html>. Acesso em: 30 dez. 2011.

PAULA, P. F.; FERREIRA, M. E. M. C. Levantamento fitogeográfico preliminar no Parque do Cinqüentenário em Maringá - PR. Geografia, Londrina, v. 14, n. 1, p. 73 - 86, 2005.

RODRIGUES, M. et al. Aves do Parque Nacional da Serra do Cipó: o Vale do Rio Cipó, Minas Gerais, Brasil. Revista Brasileira Zoologia, Curitiba, v. 22, n. 2, p. 326 - 333, 2005.

Recebido: fevereiro de 2018. Aceito: março de 2018. 